\title{
usm

\section{A produção escrita e a formação de professores}

\author{
Written production and teacher training
}

\section{* Arnaldo Nogaro}

Professor doutor na Universidade Regional Integrada do Alto Uruguai e das Missões, Erechim, Rio Grande do Sul, Brasil.

narnaldo@uricer.edu.br - http://orcid.org/0000-0003-0517-0511

\section{** Ana Paula Teixeira Porto}

Professora doutora na Universidade Regional Integrada do Alto Uruguai e das Missões, Frederico Westphalen, Rio Grande do Sul, Brasil.

anapaula@uri.edu.br

\section{*** Luana Teixeira Porto}

Professora doutora na Universidade Regional Integrada do Alto Uruguai e das Missões, Frederico Westphalen, Rio Grande do Sul, Brasil.

luana@uri.edu.br

Recebido em 21 de janeiro de 2018

Aprovado em 20 de setembro de 2018

Publicado em 11 de setembro de 2019

\section{RESUMO}

Este artigo trata da escrita como experiência de formação para estudantes e professores. Historicamente a escola assumiu como suas funções ensinar a ler e a escrever, com o passar do tempo privilegiou a leitura em detrimento da escrita, o que faz com que saiamos dela sem experiências mais significativas ou com habilidade de escrever. A investigação que originou este artigo é de natureza teórico-bibliográfica, de cunho qualitativo. A incursão na literatura permitiu encontrar autores para amparar teoricamente a reflexão e a interpretação da temática proposta. A interlocução com obras de estudiosos como Barthes, Marques, Bianchetti e Machado possibilitou o aprofundamento a respeito do escrever como prática de conhecimento e autoria, bem como alçar questionamentos e construir argumentos em favor da escrita e sua relação com a formação de professores. As descobertas permitem afirmar que a escrita é secundarizada na escola e que os professores, em sua grande maioria, temem-na e não a utilizam como experiência para a sua formação e a formação dos estudantes. A escrita pode ser um recurso poderoso em favor da inclusão e do empoderamento político, no entanto, o estranhamento em relação a ela faz com que se percam oportunidades de crescimento pessoal e de expressão de ideias.

Palavras-chave: Escrita; Formação de professores; Autoria. 


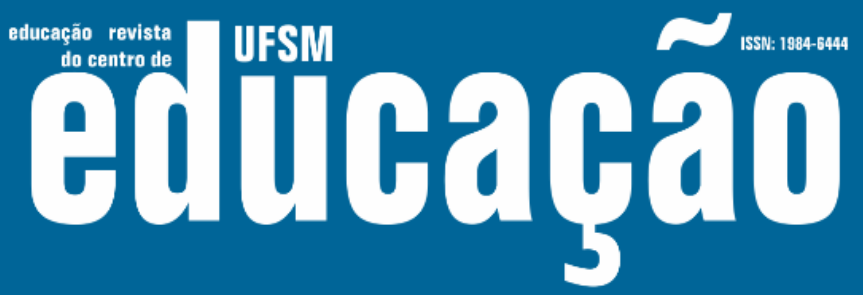

ISSN: 1984-6444 | http://dx.doi.org/10.5902/1984644430978

\section{ABSTRACT}

This article presents a discussion about the written as a training experience for students and teachers. Historically, the school has assumed the role of teaching to read and write, over time it has privileged reading over writing, which means that we leave without any more meaningful experiences or ability to write. This research is of a theoretical-bibliographic study with qualitative data analysis. The foray into the literature allowed authors to be found to theoretically support the reflection and interpretation of the proposed theme. Dialogue with works by scholars such as Barthes, Marques, Biachetti, Machado, made possible the deepening of writing as a practice of knowledge and authorship, as well as raise questions and build arguments in favor of writing and its relationship with teacher training. The findings allow us to affirm that writing is secondary in school and those teachers, for the most part, fear it and do not use it as an experience for their training and the training of students. Writing can be a powerful resource in favor of inclusion and political empowerment and the estrangement from writing can lead to loss of opportunities for personal growth and expression of ideas.

Keywords: Writing; Teacher training; Authorship.

\section{Introdução}

O século XXI sinaliza a importância de se ampliar a habilidade de escrever especialmente quando observamos resultados preocupantes quanto à habilidade de produção de textos escritos de estudantes da educação básica e do ensino superior, incluindo cursos de pós-graduação stricto sensu. Exemplos singulares desse contexto são as avaliações de redação do ENEM 2017, nas quais apenas 53 candidatos - num total de mais de quatro milhões de textos corrigidos - obtiveram nota máxima, e as redações com estruturas e linguagens bastante limitadas em dissertações de mestrado e em teses de doutorado. Essa realidade instiga-nos a repensar a escrita como instrumento não só de comunicação e informação, mas também de constituição do sujeito, além de evidenciar-se como habilidade que requer maior atenção nos processos de formação de alunos.

Para Gnerre (1998) refletir sobre a escrita torna-se quase que uma necessidade diante da difusão em nível mundial da escrita na educação básica e, ao mesmo tempo, a sua prática em moldes e formas tradicionais que parecem tornar a atividade obsoleta 


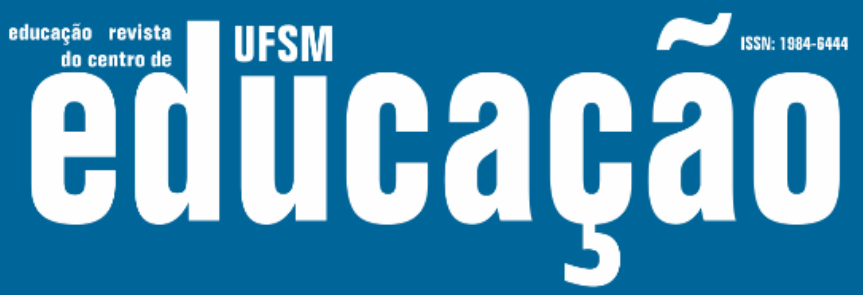

ISSN: 1984-6444 | http://dx.doi.org/10.5902/1984644430978

diante do avanço das novas tecnologias que impulsionam novos relacionamentos do sujeito com a escrita. O surgimento de diversos aparatos digitais, como iphones, e de novos dispositivos comunicacionais, como o Messenger, altera os códigos de escrita e amplia a sua prática, porém, para estar na cultura, é preciso saber ler e escrever bem. No entanto, saber escrever vai além do que registrar, a partir de um determinado código, como o verbal, informações e comunicar algo. Segundo Marques (2001, p. 13) escrevia-se o que antes se pensava: "Agora entendo o contrário: escrever para pensar, uma outra forma de conversar." Em outros termos, a escrita serve para estimular o pensamento, o raciocínio lógico, a reflexão e também para colaborar na construção e no autoconhecimento de quem escreve. A escrita, nesse sentido, é instrumento para constituição de identidade.

Ainda sob essa perspectiva, a escrita e a leitura são compreendidas como práticas sociais necessárias à formação do sujeito, ou seja, como instrumentos que possibilitam não apenas a inserção do indivíduo em diferentes contextos (sociais, históricos, culturais, profissionais), como também a ascensão para outros que não os de sua origem inicial. A leitura, na concepção de Kleiman (2013), relaciona-se à imersão do indivíduo em culturas letradas, diferente daquele em que ele que surge, e à ativação de estratégias baseadas em seu conhecimento linguístico, sociocultural e enciclopédico que poderão conduzi-lo a experiências diversificadas de compreensão de si e do mundo a seu redor. Segundo a pesquisadora, a realização de leitura exige o processamento de ações conjuntas de valores, crenças e atitudes que refletem o grupo social em que os sujeitos se inserem, assim como decorre da interação entre aspectos sociais e culturais que perpassam pela atividade intelectual inerente ao ato de ler (KLEIMAN, 2013).

Nessa lógica, como processo associado a essa formação leitura, está a escrita, compreendida também como uma prática que se associa à competência de leitura, constituindo-se em uma prática social que se fundamenta em ações de compreensão do que, como e para que se escreve numa dada situação específica em que o horizonte cultural e social também se impõe. Dessa foram, a leitura e a escrita são práticas sociais indissociáveis da cultura, do contexto do qual emergem, o que induz a creditar que é preciso "não é apenas ensinar a ler e a escrever, mas é, sobretudo, 


\section{F HEM Eutloará

ISSN: 1984-6444 | http://dx.doi.org/10.5902/1984644430978

levar os indivíduos - crianças e adultos - a fazer uso da leitura e da escrita, envolverse em práticas sociais de leitura e escrita" (SOARES, 1998, p.18).

Na visão de Bianchetti (2002), não basta saber escrever, faz-se necessário ter clareza sobre o porquê da produção escrita em favor de quem utilizá-la. No presente estágio da humanidade, a escrita impõe-se como elemento imprescindível ao domínio dos códigos de comunicação e ao acesso ao conhecimento. Embora a escrita seja reconhecida como uma habilidade a ser desenvolvida na educação básica, como apontam documentos importantes como a LDBEN, os PCNs, a Matriz de Referência do ENEM, etc., a escola ainda trabalha com o predomínio da leitura, e as pessoas que saem dela apresentam grandes dificuldades de usar adequadamente a escrita, como comprovam as avaliações das redações do ENEM, por exemplo. Nesse sentido, Kramer (2000) afirma que, de todos os modos de deixar marcas e demonstrar o que se pensa, sente, deseja ou crê, a escrita teve e tem papel central ainda não aprendido, não exercido por aqueles que fazem a história na e da escola.

Ao retomarmos a memória de autores que se preocupam ou chamam a atenção em suas obras para a importância da escrita como experiência de formação, aporte para o conhecimento ou como princípio da pesquisa, encontramos Marques (2001), Bianchetti (2008, 2002), Barthes (1975), Demo (2000, 2002), Gnerre (1998), Nóvoa, Marcelino e Ramos (2012), Vygotsky, Luria e Leontiev (1988), que dedicam obras inteiras ou partes com teor específico sobre este tema.

Ao trazermos a escrita ao debate, deixamos claro que, quando a defendemos, fazemo-lo, acreditando em sua ocorrência para diferentes finalidades e propósitos: escrita biográfica, autobiográfica, literária, investigativa, relato de experiência pedagógica, elaboração de portfólio, construção de artigos científicos e textos informativos. Estamos falando de seu uso em diferentes momentos e segmentos da vida de estudantes e professores. Referimo-nos ao um processo básico que envolve qualquer produção textual escrita: o que se escreve, para que fins se escreve, em que contexto e, por fim, como se escreve para atingir os objetivos traçados.

Nosso propósito, neste artigo, é apresentar algumas reflexões teóricas acerca da escrita, sinalizando como ela é percebida enquanto instrumento necessário à formação do sujeito. A partir disso, tecemos algumas considerações sobre possíveis 


\section{工 WFM

ISSN: 1984-6444 | http://dx.doi.org/10.5902/1984644430978

razões de a prática da escrita constituir uma atividade não habitual nem prazerosa para muitos professores, a quem cabe, na escola, a tarefa de ensinar os alunos a escrever. Essas reflexões surgem porque quem trabalha em cursos de formação de professores, em Programas de Pós-Graduação ou acompanha o trabalho dos professores nas escolas percebe as lacunas e os silenciamentos em relação à escrita. Não raro presenciamos situações de recusa à produção escrita de textos simples, além de inúmeras dificuldades elementares de redação apresentada por professores cuja formação é inclusive em nível de pós-graduação.

Um contexto que dá à escrita uma função secundária incita-nos a pensar em algumas questões que subjazem a esses resultados: qual a relevância da escrita? A escrita possui um alto grau de dificuldade e por isso fica secundarizada? A origem estaria nos processos formativos que reforçam e deixam para segunda ordem a escrita? Por que muitos professores (inclusive do Ensino Superior) possuem medo, evitam ou se sentem inseguros para escrever e passam a vida toda sem produzir um texto mais consistente ou que possa ser socializado ou publicado?

Não temos dúvidas de que há outros questionamentos tão importantes ou mais do que estes no que tange à escrita. Abordamos alguns para ancorar nossa tese sobre a necessidade de transformar o ato de produzir, escrever um texto, exercitar a escrita, uma demanda urgente nos cursos de formação de professores, bem como na pósgraduação.

A escrita emerge e progride no seio de comunidades de cultura escrita onde se cria o gosto pela escrita e o prazer coloquial enredado da leitura de forma interativa e continuada. Só se aprende a escrever, escrevendo, pela interação com a leitura de outros textos, sobretudo com os que podemos escolher por amor (e inicialmente os dos nossos pares) ou para fazer avançar as nossas obras ou aperfeiçoar as nossas vidas e recriar os nossos mundos. (NÓVOA; MARCELINO; RAMOS, 2012, p. 491).

No meio acadêmico aparecem reiteradas e sistemáticas observações a respeito da dificuldade de escrever ou da pouca habilidade que os estudantes possuem na produção de textos simples, que exigem poucos conhecimentos linguísticos. Se ficarmos atentos, veremos que isso ocorre com professores que trabalham com estudantes ingressantes no Ensino Superior até aqueles que orientam dissertações e teses. Onde estaria a causa ou as causas de tais dificuldades ou pouca 


\section{F HWM etituará

ISSN: 1984-6444 | http://dx.doi.org/10.5902/1984644430978

habilidade com a escrita? Como a escolaridade básica trata da escrita? Pensamos que cabe um pequeno questionamento a esta altura do texto: os professores que reclamam de que os alunos não escrevem ou escrevem mal seriam bons escritores? Dão exemplo de escrita aos seus alunos? Oportunizam em suas aulas tempo e tarefas que permitem desenvolver a escrita ou familiarizar-se com a produção textual? Não podemos furtar-nos a esses questionamentos, pois eles estão diretamente relacionados com a questão da não escrita ou com a relevância da escrita para os professores, sejam formadores ou atuantes na Educação básica.

Como pensar numa cultura universitária voltada para a escrita se os próprios professores formadores estão longe, ignoram-na ou não a praticam? Esta parece ser uma das primeiras questões que merecem cuidado e que devem ser problematizadas nos espaços acadêmicos.

\section{Escrita e formação de professores: impasses e desafios}

Mesmo que o desenvolvimento da habilidade de escrita seja um dos princípios para a formação de professores ${ }^{1}$, sabemos da dificuldade de instaurarmos uma "cultura da escrita" em nossos cursos de formação de professores, o que se explica por fatores diversos, entre os quais: currículos engessados que privilegiam uma formação especializada em uma área do conhecimento; carga horária reduzida para uma formação docente adequada para uma melhor qualificação profissional; maior ênfase na leitura do que na escrita, que não raro fica mais evidenciada na produção de relatórios de estágio e de trabalhos finais de graduação; concepção teórica insuficiente sobre leitura e escrita; histórico de escrita escolar como prática difícil, complexa, distante e de resultados insatisfatórios.

Esse conjunto de fatores contribui para que a produção escrita de modo específico e a relação do sujeito com a linguagem de uma forma geral sejam prejudicadas, contribuindo para um processo vicioso de relegar a escrita como forma de constituição de si. Um processo que, no âmbito da atuação profissional desses professores que as faculdades e universidades formam, tende a ser repetido no contexto escolar. Sem uma formação nas graduações que alterem essas 


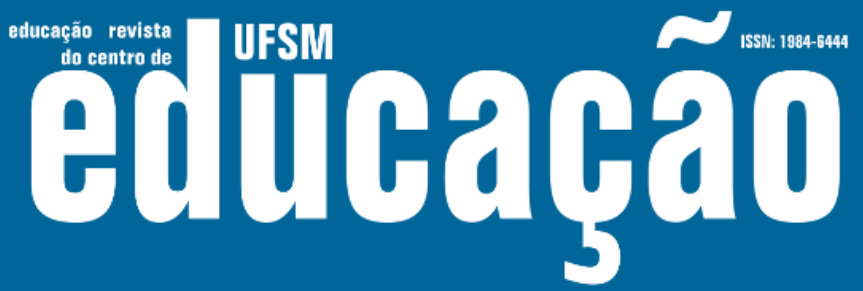

ISSN: 1984-6444 | http://dx.doi.org/10.5902/1984644430978

perspectivas, dificilmente as instituições escolares terão condições de tornar a escrita uma prática usual, prazerosa, não complexa e necessária como parte fundamental da formação humana e profissional.

No entanto, precisamos, com urgência, revermos essa questão. Fazemos essa afirmação ao concordarmos com a perspectiva de Kramer (1998, p. 20) que defende que, "para tornar seus alunos e alunas leitores e pessoas que gostem/queiram escrever, os próprios professores precisam estabelecer relações estreitas com a linguagem, experimentando a leitura e a escrita como prática social e cultural." Temos maiores condições de nos compreendermos à medida que sabemos ler quem somos, como somos, por que nos constituímos de determinada forma. Tudo isso perpassa a relação do sujeito com a linguagem. Quando escrevemos, damos voz a nós mesmos, fazemo-nos ouvir, contamos a nossa própria história e, ao escrevermos, também nos constituímos, revelamos nosso olhar sobre o mundo.

As habilidades de ler e escrever - essenciais em qualquer contexto não apenas para as práticas sociais, mas também para enfrentar os desafios profissionais requerem uma aproximação do sujeito com os diferentes usos da linguagem, e isso só se torna possível quanto se pratica esses usos. Essa prática se amplia na formação escolar quando, já no processo de alfabetização, a leitura vai se tornando mais aprimorada e a escrita, associada ao letramento, começa a surgir como uma nova descoberta. No entanto, esse processo se consolida e traz excelentes resultados quando os professores compreendem o quanto ele é fundamental para o desenvolvimento do educando, o que supõe uma formação teórica e prática para esse entendimento.

Como afirma Bianchetti (2008), a transformação do processo de escrita em objeto de reflexão e pesquisa formal, sistemática, é recente, particularmente no que diz respeito à díade escrever/publicar. As exigências quanto ao processo de escrita emergem de diferentes nuances, sejam elas de cunho formativo, dadas as deficiências na formação do sujeito que escreve ao longo de toda a sua trajetória escolar e universitária, ou formal, pois a associação entre conhecimentos teóricos e linguísticos nem sempre está associada a uma prática de produção textual escrita. 


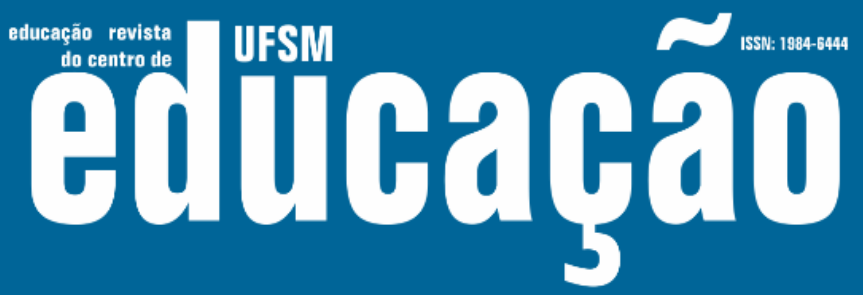

ISSN: 1984-6444 | http://dx.doi.org/10.5902/1984644430978

Neste texto, fazendo referência à formação de professores nos cursos de graduação e pós-graduação, argumentaremos em favor da escrita como prática que permite a reconstrução do conhecimento, principia a atividade de pesquisa, instala a autoria no sujeito que escreve e cria novas formas de comunicação e disseminação de conhecimento. Poderíamos buscar argumentos de outra natureza como as exigências dos mecanismos regulatórios do Ministério da Educação que, em seus instrumentos avaliativos, preveem itens específicos para a produção escrita dos docentes ou os Planos de Carreira ou de gratidão diferenciada para quem escreve.

Vamos nos ater aos de ordem formativa (sem desconsiderar outros argumentos), pois nossa preocupação, neste momento, centra-se em demonstrar o quanto a escrita pode contribuir ou alavancar a aprendizagem ou a autoria dos estudantes, especialmente aqueles que serão professores e responsáveis por levar essa prática aos níveis iniciais de escolaridade. É lá que, não poucas vezes, consolidamos habilidades e competências que as crianças e jovens levarão para a vida toda.

Entendemos nessa perspectiva que, para estimular o gosto pela escrita no diaa-dia profissional docente nas escolas, os professores precisam não só saber escrever, reconhecendo as etapas desse processo, mas também realizar a prática de escrita como algo habitual, prazeroso e necessário para se inserir no contexto que demanda essas habilidades. Além disso, acreditamos que, para ensinar os alunos a escrever, é indispensável escrever. É difícil ou quase impossível ensinar o que se desconhece ou desenvolver uma prática que não se tem.

Para que a produção escrita seja melhor compreendida nesse contexto, podemos pensar em fatores que a dificultam. Bianchetti (2008) faz referência a inibidores da escrita, fatores que a interferem, bloqueando a ação e, em muitos casos, já na intenção do ato de escrever. E um deles está relacionado com o temor da exposição das próprias ideias. Quando escrevemos, o fazemos para um leitor, sabemos que se tornará público e também sabemos que o texto adquire relativa autonomia em relação a quem o produz. Enquanto que, na fala, pode haver margem ou espaço para esclarecimentos, na escrita, isso não ocorre: "Com o escrito, não há 


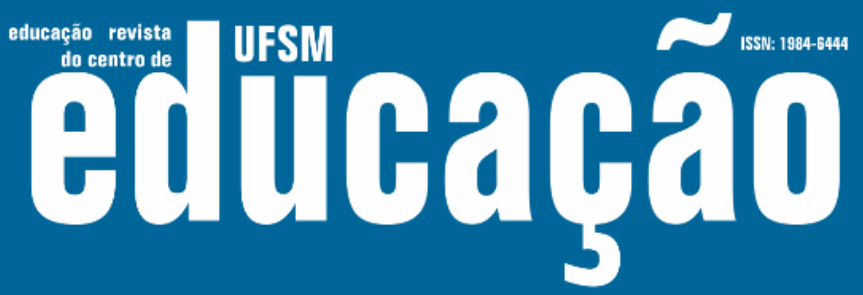

ISSN: 1984-6444 | http://dx.doi.org/10.5902/1984644430978

essa possibilidade. Isso significa que ele tem de ser claro. Precisa bastar-se." (BIANCHETTI, 2008, p. 249).

Esses dois fatores - exposição ao outro e texto autônomo - são nuances do processo de escrever que precisam ser exploradas na formação de alunos. É preciso deixar claro que, ao expor ideias em um texto escrito, deve-se ter o cuidado de como exteriorizá-las, o que exige a habilidade no uso da linguagem e escolha da estrutura textual a ser explorada. Uma habilidade que deve ser desenvolvida ao longo da formação básica para que quem escreve vá se familiarizando com esse processo e reconhecendo que há várias formas de apresentar uma ideia. A autonomia do texto deve ser percebida com o trabalho do leitor: depois de elaborado o texto, a interpretação é atividade de quem o lê que, com a bagagem cultural, linguística, social, histórica, etc., de que dispõe, vai construindo os sentidos para as palavras do texto. Nesse processo, o autor não pode intervir.

Assim não temos mais o controle sobre o texto que escrevemos, sobre seus efeitos e o que ele pode provocar, daí o desespero, pois ele desnuda, revela possível fragilidade de quem escreve. Marques (2001) argumenta que, no ato de escrever, sentimo-nos donos do próprio texto, podemos mudá-lo a qualquer momento, até destruí-lo. "Quando, porém, ele ganha mundo, quando passa ao domínio público, sinto que fugiu, emancipou-se, escapou de meu alcance" (MARQUES, 2001, p. 25).

Por essas razões, no entender de Bianchetti (2008, p. 243), quem escreve precisa ter a consciência e a preocupação de garantir um escrito tão claro que seja capaz de autossustentar-se: "O texto precisa ser autorreferente, uma vez que o autor não poderá acompanhar o escrito na sua trajetória e no consumo por parte dos leitores." Como se atinge esse nível de escrita é uma questão pertinente e para qual podemos assinalar uma possível solução: com conhecimento e prática. Só se aprende a escrever com clareza e adequação ao contexto de produção e recepção, escrevendo, reescrevendo, associando os conhecimentos sobre linguagem à prática de produção textual. Não há outro caminho. É um processo que se desenvolve ao longo da formação escolar e universitária e nem sempre ocorre com facilidade.

Dessa forma, escrever é desafiador porque a escrita obriga-nos à interlocução. "Escrever é isso aí: interlocução." (MARQUES, 2001, p. 24). O escrever está 


\section{Fusm EUtrathâ}

ISSN: 1984-6444 | http://dx.doi.org/10.5902/1984644430978

relacionado a alguém que vai ler, assim quando surge o autor, cria-se concomitantemente o leitor, mesmo que não o identifiquemos ou possamos saber quem é. Marques (2001) postula que quem escreve procura amigos para conversar. Nesse processo de busca por interlocutores, não se deve eximir de pensar no processo de produção a que aludimos no início de nossa reflexão. Ou seja, é preciso pontuar o que escrever, em que circunstância, para se produzir.

Os motivos de quem escreve são tantos quanto a imaginação permite. Freire (2002) revelou que escrevia quando algo o indignava e, portanto, usava sua caneta e papel para materializar seu inconformismo e para transmiti-lo, contaminar para que pudessem fazer coro com o que pensava. Havia um objetivo ao escrever, um processo que sempre deve ser cumprido por todos ao escrever qualquer texto para qualquer leitor. Em outros termos, para escrever, é preciso refletir sobre o contexto de produção (direcionado a quem escreve) e de recepção (associado aos destinatários da escrita). "Pois é, escrever é isso aí: iniciar uma conversa com interlocutores invisíveis, impensáveis, virtuais apenas, sequer imaginados de carne e ossos, mas sempre ativamente presentes." (MARQUES, 2001, p. 13). Assim como Calvino (1993) revela que a leitura de um clássico é sempre uma releitura, a escrita é sempre reescritura, reinterpretação, reconstrução de sentido, justamente porque aos leitores cabe à interpretação do que leem.

O leitor mantém com o escritor uma relação cheia de mistérios e indagações. Ao escrever, não sabemos quem vai ler, como vai reagir, interpretar, compreender. 0 contexto social, cultural, econômico, linguístico no qual o leitor está inserido interfere na leitura que é realizada. Leitores provindos de realidades distintas tendem a realizar leituras diferentes porque, ao ler, o conhecimento de mundo e os conhecimentos linguísticos, históricos, sociais e culturais intervêm. Logo, a leitura sempre é um campo aberto sobre o qual aquele que escreve não tem qualquer controle.

Mesmo que tenhamos conhecimento de alguns traços comuns de nossos leitores, ao certo não sabemos, tudo fica no campo da "aventura." (MARQUES, 2003). Para Marques (2001) tudo isso ocorre num "silêncio" estarrecedor que gera calafrios em quem escreve, sem dizer uma palavra. "Uma mudez que incomoda, provocadora e desafiante. Seria mais tranquilo ouvir a voz desse interlocutor, perceber como nos 


\section{W Lism EItlagha}

ISSN: 1984-6444 | http://dx.doi.org/10.5902/1984644430978

está interpretando, o que nos tem a dizer. Ele mudo, porém, se faz muito exigente e crítico, porque a mim transfere esses cuidados." (MARQUES, 2001, p. 21)

Se é tão complicado, tão difícil e nos expõe, por que então escrevemos? Alguns não se sentem encorajados em função de não sentirem necessidade e vão fazê-lo somente no momento que a premência do cotidiano o exigir: trabalhos acadêmicos, monografias, dissertações, teses, relatórios, sistematização de reuniões, etc. Sabemos muito bem que cada exigência dessas tem seu grau de complexidade e possui níveis de profundidade diferentes, o que transforma a prática de escrita em algo controlável ou assustador. "A insegurança, o medo da exposição, o desconforto da vulnerabilidade são sentimentos que não se restringem apenas ao espaço-tempo da pós-graduação, como apontamos." (BIANCHETTI, 2008, p. 247).

O que o ato de escrever envolve que provoca pânico ou apavora as pessoas? Seria o fato de ser um elemento não constituinte de nossa natureza animal, ser um artefato ou produto da cultura que precisamos desenvolver ou exercitar para nos tornarmos exímios nisto. Comprovadamente trata-se de um artefato cultural inventado pelo homem e com o qual precisamos nos familiarizar para adentrar à cultura, aos conceitos científicos, comunicar-nos, transmitir emoções, enfim, interagir no meio social onde vivemos. O domínio da escrita permite-nos estabelecer e manter relacionamentos com outras pessoas.

Nóvoa, Marcelino e Ramos (2012) lamentam que os professores não tenham consciência de que seus instrumentos profissionais são os instrumentos de trabalho intelectual, dentre os quais está um poderosíssimo artefato construído pela cultura humana que é a escrita e com a qual possuem pouca intimidade, estão afastados e não a utilizam em todo seu potencial para a aprendizagem dos estudantes.

Os professores têm medo da escrita, não estão à vontade na escrita, têm medo de perceber que ela é decisiva para a construção das aprendizagens dos alunos, parecem ignorar que o falar e o escrever é que constroem o conhecimento. É através da ação de construção de textos pela fala e pela escrita que se constrói também o conhecimento. Esta falta de consciência leva a que só o professor é que fala. Mas o aluno não pode falar o conhecimento, está impedido de utilizar uma estratégia fortíssima para a construção do conhecimento. (NÓVOA; MARCELINO; RAMOS, 2012, p. 499500). 


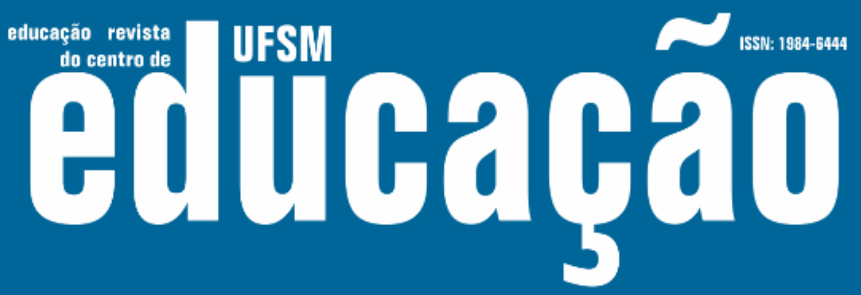

ISSN: 1984-6444 | http://dx.doi.org/10.5902/1984644430978

A escrita é aprendida na escola, mas também fora dela e é reconhecida como uma habilidade associada à inclusão e à exclusão, pois, conforme Nóvoa, Marcelino e Ramos (2012), a escrita pode incluir como excluir as pessoas no contexto social

\footnotetext{
"A situação é de tal forma clamorosa que os professores nem ousam avisar os seus alunos, por lealdade, de quanto a falta de domínio da escrita os discrimina, contribuindo largamente para a sua exclusão da escola, que os arrasta, inevitavelmente, para a exclusão social" (NÓVOA; MARCELINO; RAMOS, 2012, p. 523)
}

Saber escrever é, nesse sentido, uma forma de inclusão social porque, à medida de que o sujeito sabe se expor verbalmente através de textos escritos, distingue-se de significativa parcela da população. A escrita consolida-se assim como instrumento de empoderamento para, ao mesmo tempo de dar voz ao sujeito, colocálo em uma posição de maior destaque, já que, através da manifestação escrita, marcam-se também as relações de poder. Quando há o domínio da variação culta da língua escrita, maior empoderamento linguístico se consolida especialmente em contextos tradicionais nos quais essa variante é a única reconhecida como adequada e legítima.

O acesso à variante culta, prestigiada social e historicamente, é um dos entraves à produção escrita porque nem todos os sujeitos têm acesso a ela, e a escola, instituição que deve ensiná-la, tem dificuldades de realizar esse processo sem acarretar problemas aos alunos. Um processo que em muitos casos se estende no ensino superior. Isso justifica, por exemplo, o medo de escrever para muitos, especialmente para quem vem de contextos socialmente desfavorecidos em que a variante culta e a escrita não fazem parte do cotidiano.

No caso da escrita como prática de professores, esse contexto também se mantém. É comum que alunos das licenciaturas e professores já graduados tenham dificuldade em se expressar por escrito e tenham receio em escrever ou até mesmo evitem ao máximo essa atividade. Experiências assim podem incidir em uma tendência quando lecionarem na educação básica: desprestígio da produção escrita como uma prática necessária para formação do sujeito, empoderamento social, construção de identidade e autoria, expressão de pontos de vista, etc. Essa é uma perspectiva que precisa ser discutida e limitada. Nóvoa, Marcelino e Ramos (2012) 


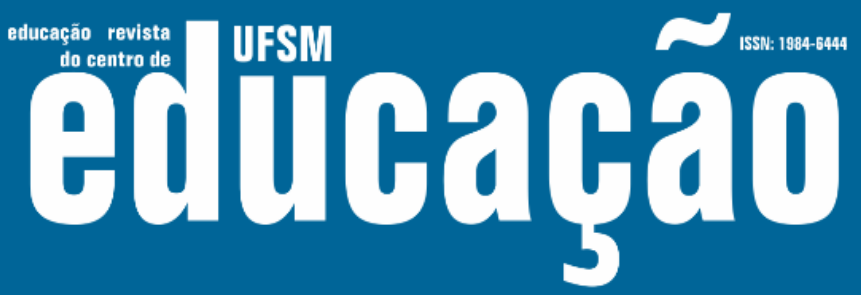

ISSN: 1984-6444 | http://dx.doi.org/10.5902/1984644430978

questionam como o professor pode sustentar-se em seu trabalho e ser um bom profissional, tendo medo da escrita:

Presos como estamos ao policiamento da escrita dos nossos alunos, dificilmente encaramos a escrita como libertação e apoio aos nossos atos profissionais. E, no entanto, é a escrita o alicerce e o andaime do nosso ofício de trabalhadores intelectuais. É alicerce, porque é em textos que o saber da profissão se funda. É andaime, porque se sustenta de fora e na tessitura da escrita a construção intelectual da profissão que escolhemos. (NÓVOA; MARCELINO; RAMOS, 2012, p. 403).

$\mathrm{Na}$ folha em branco, há uma dicotomia nem sempre percebida. O que aflora é o branco vazio que assusta, no entanto, ele é o sustento e a possibilidade de a escrita fluir. Ela dá suporte ao escrever e dará também a muitas leituras divergentes, diferentes, similares ou antagônicas, mas sempre leituras. Essas novas leituras que são construídas e ressignificadas podem ter na produção escrita uma possibilidade de exposição, assim como de melhor compreensão porque, à medida que escrevemos, também podemos qualificar a nossa percepção sobre o tema o qual discorrermos. A leitura, nesse sentido, é uma atividade que perpassa o trabalho de escrever.

Machado (2008, p. 270) afirma que a escola tem demonstrado inabilidade quando se trata de promover o domínio e usufruto dessa tecnologia tão simples, "tão poderosa quanto uma arma", que é a escrita. Não é constatação somente sua, vários outros pensadores têm manifestado suas ideias nesta direção e, o que podemos fazer de mais empírico neste sentido, é cada um de nós retroceder e pensar em nossas histórias de vida na escola e procurar identificar em nossas lembranças situações ou ocasiões em que houve ênfase, trabalho pedagógico orientado para a escrita. Quem e quando alguém trabalhou comigo? Contigo? Com cada um de nós? De que nos lembramos? Por que temos medo da escrita? Por que não a vivenciamos, não exercitamos ao longo de nossa vida escolar? Quanto tempo da vida escolar de uma criança ela passa escrevendo? Com a invenção de xérox, impressoras, livros didáticos, o que sobrou para a escrita?

As origens do temor paralisante da escrita parecem não estar tão bem esclarecidas ou explicitadas, temos hipóteses, muitas por se confirmar, outras mais ou menos conhecidas, mas há uma que merece uma atenção especial, uma 


\section{F HWM Eulloahâ}

ISSN: 1984-6444 | http://dx.doi.org/10.5902/1984644430978

compreensão mais acurada, mais profunda, no dizer de Machado (2008) possui uma natureza psicanalítica, associada à certa dose de sofrimento. Está relacionada com a forma como organizamos o trabalho da escola e a cobrança que fazemos em relação à escrita. Não são poucas as histórias relatadas do uso da escrita como castigo que camuflam o papel atribuído à escrita como prática: "errou, vai escrever mais x vezes"; "não está interessado na aula, vai escrever uma redação"; "está perturbando os colegas, vai para a biblioteca copiar um texto"; e assim iríamos descrevendo muitas outras situações com as quais nos deparamos cotidianamente na escola. Que lembranças uma criança ou jovem guarda da escrita após passar por uma situação dessas? Kramer (2000, p. 108) ressalta que "[...] substitui-se a autoria pela autorização e impede-se que a escrita com significado seja produzida." Para ela, ainda não aprendemos a explorar o potencial de criação da escrita, e insistimos numa escrita instrumental, funcional, repetitiva, mecânica e esvaziada de sentido.

Soma-se a isso o fato de que o professor avalia os alunos, de forma predominante, por meio de trabalhos escritos, o que faz induzir ao pensamento de que a escrita "só" serve para provas, testes e trabalhos, configurando-a a uma prática limitadora, reducionista de seu papel como instrumento de constituição do ser na sociedade. Em contextos assim, dentre as funções possíveis da escrita como comunicar-se com os pares, expressar ideias, etc, o que se reforça é a prática do "julgamento" ou "avaliação" pelo que se escreve. Segundo Evangelista (2002), não raramente os trabalhos escritos pelos alunos se consolidam como formas destituídas de vida, seja pelo ritual avaliativo mecanicamente cumprido por eles, seja pelo descaso com que são tratados por quem os solicita.

Para Barthes (1975) ensina-se a criança a ler bem, mas, no fundo, não se a ensina a escrever. Nas instituições educacionais, de quem é a responsabilidade ou qual é a área do conhecimento, disciplina que deve despertar, desenvolver e exercitar a escrita? De todos os professores, de todas as disciplinas, sem exceção. Há umas que se prestam mais do que as outras pelas suas especificidades (mais teóricas, abordam temas do cotidiano), mas não cabe exceção porque a escrita perpassa todas as áreas de conhecimento, mas essencialmente porque está intimamente relacionada 


\section{Autตaดูão}

ISSN: 1984-6444 | http://dx.doi.org/10.5902/1984644430978

à construção do sujeito, e esse processo se dá em todos os campos do saber e não em um em particular.

Contudo, na escola há uma hierarquia de responsabilidade: primeiro a Língua Portuguesa, depois a Literatura e Redação, seguindo a Filosofia e a Sociologia, História, e assim segue, até de certa forma com a legitimação de documentos oficiais como os PCNs, que acentuam a habilidade de escrever para o campo de atuação de Língua Portuguesa. Essa é a crença que precisa ser abalada, romper com a concepção de a escrita pertencer a uma área ou disciplina, pois "[...] não se produz ciência sem registros." (MACHADO, 2008, p. 275), não se formam sujeitos e profissionais sem linguagem, não se conclui uma graduação em qualquer área sem escrever.

Machado (2008, p. 276) conclui que, de certa maneira, a escola assumiu a bandeira da escrita como sua responsabilidade, mas não está conseguindo cumprir. A escola "[...] tem mostrado dificuldades em admitir esses saberes e incorporá-los, restringindo os trabalhos de iniciação ao universo escrito a questões instrumentais, esvaziadas de sentido." Os resultados disso: falta de empatia e de habilidades com a escrita; desempenhos alarmantes de alunos em produções textuais escritas; incompreensão do papel fundamental que ela exerce enquanto instrumento de formação e atuação cidadã.

Escrever envolve pôr em xeque nosso ego, uma vez que, ao dar vasão a nossas ideias e registrá-las por meio da escrita, expomos nossa intimidade, nossos pensamentos; depois que escrevemos, aparecem coisas boas, vêm elogios, mas também surgem os críticos, nossas fraquezas são percebidas, por isso que Machado (2008) diz ser a escrita uma forma de "exibição" mais discreta.

No caso da escrita, a exibição está incorporada na inscrição das ideias em um suporte que não o corpo de seu autor, um suporte que pode ter várias substâncias: a casca da árvore, a pedra, o papel, a tela, os sites dos servidores da internet, etc. A exibição está presente na hora de escrever, como possibilidade ameaçadora, mas não necessariamente consciente para quem escreve. (MACHADO, 2008, p. 281).

Quando falamos de prática de escrita, temos em mente a comparação que alguns teóricos fazem da escrita com as práticas do movimento humano. Em outras 


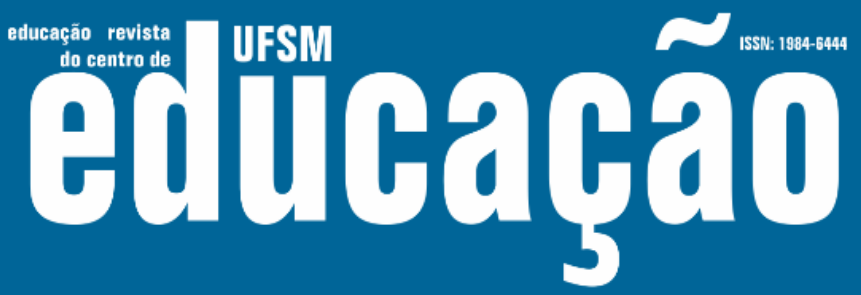

ISSN: 1984-6444 | http://dx.doi.org/10.5902/1984644430978

palavras, escrever é um exercício que, quanto mais praticarmos, melhor nos tornamos. É por isso que questionamos os espaços/tempos de escrita (ou não escrita) de nossas trajetórias escolares. Como sermos bons, termos uma habilidade desenvolvida se pouco ou quase nada foi trabalhado?

Talvez, até chegarmos a construir ou organizar nossas próprias ideias, tenhamos que exercitar a escrita com as ideias ou pensamentos dos outros, para isso nos valemos do que já foi escrito ou produzido pelos teóricos, poetas, cientistas. Usamos seus textos e vejamos que há algo a se pensar a este respeito, pois a palavra "texto" remete a trama, tecer, entrelaçar, isto é, construir um texto é entrelaçar ideias, cruzar pensamentos, portanto, o texto precisa ser pensado como processo e não como produto acabado, só assim teremos lugar para o aparecimento da autoria, das ideias próprias. No entender de Girardello (2008), precisamos estimular a formação de alguém capaz de dizer alguma coisa nova ou de forma nova, que contribua para a compreensão dos fenômenos do mundo.

Desta forma, a autoria nasce ou se constrói a partir do texto do outro, o que nos leva à importância da leitura. "A relação entre a leitura e a produção textual é obviamente central para a fase preliminar da escrita acadêmica." (GIRARDELLO, 2008, p. 293). No caso específico da escrita, um caminho precisa ser percorrido: ver nela um instrumento de formação indispensável a todos e, no caso de professores, algo vital para que possa se reconhecer como sujeito que se constitui também ao escrever e como alguém que, somente com a prática de escrita, será capaz também de estimular seus alunos a escrever e ainda a escrever bem para não ser excluído socialmente.

Ao tematizarmos a escrita e a formação de professores, não temos a pretensão de criar uma "obrigação" de escrita nas instituições formadoras. O que objetamos mostrar é o quanto a escrita pode ser um "[...] meio de posicionamento e de intervenção", que sirva de estratégia para contribuir com seu próprio "[...] esclarecimento e sua inserção histórico-social." (BIANCHETTI, 2008, p. 262). A escrita provoca o aparecimento do sujeito, tira-o do anonimato, insere-o num contexto, permite que diga sua palavra (FREIRE, 2002), resgata-o do silenciamento. 


\section{DIFSM entubará}

ISSN: 1984-6444 | http://dx.doi.org/10.5902/1984644430978

Os professores, como profissionais e categoria que trabalha com conhecimento, precisam fazer uso da escrita para estabelecer conexões, comunicarse, externar o que pensam para que não fiquem à mercê dos discursos "prontos" que vêm de fora, dos que tudo sabem em detrimento do saber de quem está no ato cotidiano de educar. Bianchetti (2002, p. 98) situa a categoria dos professores dentro daquelas que devem usar a "arma do escrever": "Manejar esta arma é uma das condições para desempenharem com dignidade a profissão docente. [...] é tão impensável imaginar um professor que não escreve, quanto imaginar um pedreiro que não saiba manejar uma espátula."

Kramer (2000) enfatiza que a leitura e a escrita precisam ser elementos constituintes da formação, da escola de educação básica ao ensino superior e defende que sejam oportunizadas experiências de formação com base na escrita e na leitura, só assim vai-se superar ou romper com os estranhamentos em relação a elas. Nóvoa, Marcelino e Ramos (2012) vislumbram a escrita como algo intrínseco ao ser e ao fazer docente, sendo ela elemento diferenciador da ação e do trabalho do professor, seja na sala de aula ou fora dela. Veem-na como mecanismo de afirmação profissional e de identidade profissional.

\footnotetext{
É na escrita, como espelho, que melhor podemos ver a incompletude dos nossos esforços. É nela que apoiamos a forma do que pensamos. É nela que assentamos o desenho do que projetamos alcançar. É com ela ainda que contamos, para demarcar e definir o conhecimento em que vamos avançando. Com ela, finalmente, dizemos aos outros de tudo isto, e da emoção que pomos nos caminhos que vamos prosseguindo, na direção que escolhemos para a profissão que, com a mesma escrita, poderemos estruturar com mais acerto e segurança. (NÓVOA; MARCELINO; RAMOS, 2012, p. 404).
}

De onde devemos partir para instaurar uma "cultura da escrita" em nossos espaços de formação de professores? Escrever exige um mote, uma razão, um desafio inicial, uma provocação, mas o que vai sustentar nossos argumentos daí em diante diz respeito ao suporte teórico que temos, a riqueza das ideias que conseguimos produzir ou externar. Para Marques (2001, p. 17), sem o "[...] suporte físico da folha e sem o suporte histórico da gramática e do dicionário não se escreve de forma a ser entendido." Veiga-Neto (2012) enfatiza que "é preciso ir aos porões", 


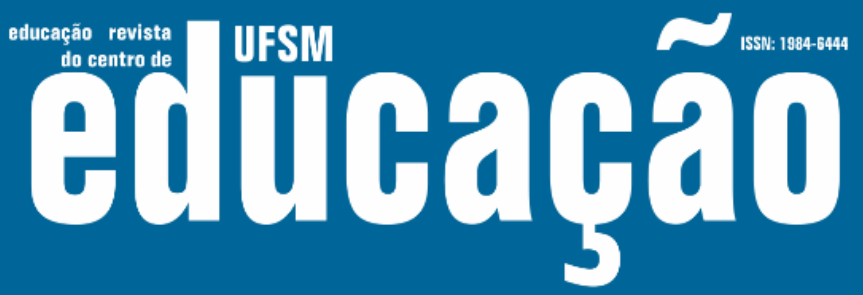

ISSN: 1984-6444 | http://dx.doi.org/10.5902/1984644430978

ou seja, consultar, ler, socorrer-se de pensadores e teorias que sirvam de sustentáculo para nossos argumentos. $O$ autor vale-se da metáfora da casa e situa no porão o que é valioso e que precisa ser resgatado. Os porões podem servir de apoio e ancoradouro para nossas fragilidades e inseguranças. "Além do mais, as descidas aos porões nos potencializam sobremaneira para enfrentarmos racionalmente tais fenômenos, trabalhando a favor daquilo que nos interessa e contra os constrangimentos e limitações que se nos impõem." (VEIGA-NETO, 2012, p. 268).

Ao comparar a casa com a pedagogia, insiste na necessidade de valorizarmos e ocuparmos todos os cômodos e termos vigilância epistemológica para não nos perdermos em modismos e banalidades que levem a automatismos e pragmatismos sem maior reflexão. "Poucos descem aos fundamentos nos quais se enraízam suas opções epistemológicas e, consequentemente, poucos conhecem o subsolo em que se alimentam suas conviç̧ões acerca da salvação por obra da educação." (VEIGANETO, 2012, p. 276). Sem saber o que se encontra nos porões, valemo-nos de soluções milagrosas, alternativas superficiais. Conhecer o que se passa nos porões pode nos ajudar a identificar as raízes de muitas práticas ou fenômenos educacionais que lá possuem suas raízes. É lá nos porões que podem estar muitas saídas e soluções, dentre as quais retomar o papel ou o sentido da escrita como princípio do conhecimento, da pesquisa e da consistência da formação de professores, pois muitos que saem das casas de formação nem sempre são razoáveis leitores, que dirá bons escritores. Como imaginar um bom professor que não saiba se comunicar adequadamente e em linguagem fluente, pela fala e pela escrita? Pensemos sobre isso.

\section{Considerações finais}

Ao defendermos a prática da escrita não o fazemos por motivos banais como "escrever por escrever, para praticar", mas temos consciência dos seus resultados, do que ela produz em quem escreve, principalmente à sua relação com o armazenamento de informações/conhecimentos e dos "alargamentos" da mente que ela produz. No entender de Evangelista (2002), na escrita cria-se o solo sobre o qual 


\section{HEM Eutlagha}

ISSN: 1984-6444 | http://dx.doi.org/10.5902/1984644430978

a cultura, sob a forma de conhecimento, deixará de ser externa ao aluno para constituí-lo vitalmente.

A escrita alarga os processos de compreensão da mente humana. Segundo Vygotsky, Luria e Leontiev (1988, p. 188), "[...] não é a compreensão que gera o ato, mas é muito mais o ato que produza compreensão - na verdade, o ato frequentemente precede a compreensão." O ato de escrever precede um processo de compreensão, o que significa pensar que quando não conseguimos elaborar o pensamento e manifestá-lo por escrito, isto revela que algo não foi compreendido, o que denuncia que a própria leitura, em muitas situações, fica comprometida ou produz pouco efeito, pois dela pouco ou quase nada conseguimos inferir ou descrever. Escrever ou produzir um texto após uma leitura demonstra que houve um processo de compreensão, de entendimento que o possibilitou. Logo, tem-se uma das principais funções da escrita: registro de informações e de conhecimentos.

Atualmente dispomos de vários suportes para escrita. O lápis ou o computador, por exemplo. Porém, mais importante do que é essa escolha, o que queremos é deixar claro que, seja por um mecanismo ou outro, o que não podemos deixar de lado é a escrita. É sobre ela que queremos tematizar para demonstrar sua relevância para a aprendizagem e para a formação docente. Mas há um ponto que nos parece indiscutível: lápis ou computador não escrevem sozinhos, não produzem ideias. São ferramentas que podemos usar para materializar na escrita nossos pensamentos e com isso ter uma formação mais qualificada que dê conta de, nas práticas profissionais docentes, instituir o papel que de fato cabe à escrita, sem renegá-la como atividade punitiva, enfadonha, desnecessária ou distante das possibilidades discentes.

Reconhecemos que esse redirecionamento da escrita como prática escolar e cotidiana não é fácil especialmente quando o ato de escrever concorre com o ato de copiar/colar dadas as facilidades de acesso às informações nas redes. O que é grave hoje na academia é a crença de que a internet resolve tudo, tornou-se a conselheiramor, em detrimento da criatividade e do desenvolvimento da inteligência. Podemos usar o que está na rede? Sem dúvida, o que não podemos fazer é mera cópia, transposição de um lugar para outro sem interpretação, sem reconstrução, sem 


\section{Hism Eutthab̧a}

ISSN: 1984-6444 | http://dx.doi.org/10.5902/1984644430978

acréscimo, sem crítica. Porém tudo isso perpassa o trabalho de escrita e, nesse contexto, este parece ser um dos dramas mais acentuados da vida acadêmica.

Associando-se ao não escrever e ao escrever mal, vai surgindo um novo problema: a dificuldade de construção de autoria no sentido de que se enfatiza a reprodução e menos a produção (de informações, ideias, teses, conhecimentos). Estamos perdendo a autoria, estranhando-nos da produção própria. A dimensão criativa, reflexiva da pesquisa cedeu lugar para o texto mosaico resultante do copiar e colar e, não poucas vezes, sem referir a autoria da ideia, reforçando o plágio e o furto intelectual - problemas que precisam ser combatidos na formação de professores para que estes, reconhecendo cenários assim, possam ter condições de apontar os caminhos adequados de produção, inclusive de produção textual escrita.

Nóvoa, Marcelino e Ramos (2012) são enfáticos a respeito da necessidade de rever a organização pedagógica da escola e, de forma urgente, repensar os processos de aprendizagem centrados na figura do professor, no silenciamento do estudante e na responsabilização do indivíduo isolado pela não aprendizagem. O diálogo, a sistematização, a reconstrução escrita das ideias no coletivo tornam-se decisivas para a emancipação do sujeito e de sua cidadania.

A apropriação do conhecimento faz-se pela construção e pela ação, pela fala e pela escrita, e não é possível construir aprendizagens sem falar e escrever as aprendizagens. A construção do conhecimento, historicamente, foi sempre feite assim: dialogando, escrevendo. É necessário criar ambientes onde os alunos possam falar, possam dizer o conhecimento, escrever o conhecimento e pô-lo a circular, principalmente na sua comunidade, para perceberem, desde logo, como conhecer é socialmente útil. (NÓVOA; MARCELINO; RAMOS, 2012, p. 515).

Falamos desta questão, pois no texto tratamos das exigências da escrita e do esforço que ela demanda para que se instaure como "cultura do indivíduo". É claro que a vida moderna demanda que automatizamos muitos processos para economizarmos tempo/esforço e "queimar" menos neurônios, mas há tarefas que demandam esforço mais prolongado em razão de sua complexidade, e a escrita é uma delas. Claro que quanto mais escrevemos, melhor nos tornamos, mas ela possui níveis de exigências diferenciadas de outras atividades. $E$ isto muitas vezes faz com que as pessoas se afastem ou não se sintam motivadas para tal. 


\section{F HWM EUtrathâ}

ISSN: 1984-6444 | http://dx.doi.org/10.5902/1984644430978

$O$ ato de escrever reestrutura a mente do ser humano, novas conexões formam-se, reforçam-se, reconfiguram-se. A neurociência denomina de aprendizagem quando há uma modificação do cérebro pela experiência e a leitura e escrita oportunizam experiências singulares para que o cérebro se modifique. Aos saberes existentes em nossa mente, por meio da leitura da escrita, outros virão associar-se. Conforme Marques (2001, p. 26), os saberes da cada interlocutor entram em jogo, se fundem, se transformam, reformulam-se. "De maneira muito especial, meus saberes anteriores se configuram agora outros. A isso chamamos de aprendizagem."

Gnerre (1998, p. 60) recomenda que, no trabalho de alfabetização, temos que encontrar estratégias que contribuem para "[...] novas atitudes em relação à escrita, que sugiram hipóteses interessantes sobre o uso e as funções da escrita e que, longe de apressar o processo de alfabetização, tratem de preparar o contexto psicológico e sociocultural mais adequado para que ele se realize." Ampliando essa perspectiva, podemos afirmar que é necessário ir além no sentido de alertar os educandos sobre a importância da escrita não apenas como instrumento de comunicação, mas também como meio de constituição e empoderamento do sujeito.

Os teóricos elencados ao longo do texto nos auxiliam e dão sustento a nossos argumentos na direção de pleitearmos processos formativos, seja na escola básica ou na universidade sustentados na escrita. A inteligência linguística sustenta-se muito sobre a leitura, a oralidade e a escrita. Mas, esta produz impactos na mente das pessoas de forma diferenciada das demais. Trata-se de um mecanismo mais profundo e para o qual precisamos de maior esforço e exercício, o que vale tanto para a formação de professores quanto para os resultados que um podem surgir quando da atuação desses alunos como professores escolares.

Ao finalizarmos essas reflexões, retomamos questões-chave apresentadas no início de nossa discussão. A primeira delas relaciona-se à relevância da escrita, compreendida, como uma prática necessária cujos meios de realizá-la, nos espaços institucionais formativos tanto da educação básica quanto do ensino superior, carecem de novas concepções sobre a escrita e novas possibilidades de desenvolvêla sem rotulá-la como algo pouco útil ou difícil, como uma "tarefa" a ser cumprida. 


\section{Autดaคูão}

ISSN: 1984-6444 | http://dx.doi.org/10.5902/1984644430978

Quanto ao alto grau de dificuldade de escrita e, como efeito, um possível lugar secundário atribuído a ela se comparada com a leitura, também temos que fazer três ponderações. A primeira: as dificuldades estão associadas inicialmente a problemas de compreensão - inclusive teórica - da escrita por parte de professores e também à forma como a produção escrita é desenvolvida ao longo da formação dos sujeitos. A segunda: a escrita, assim como a leitura, precisa ser vista como habilidade a ser amplamente desenvolvida de forma equilibrada sem privilégio de uma ou de outra e em todas as áreas do conhecimento, pois ninguém se forma e se transforma sem ler e escrever. A terceira: ao se ter um processo formativo voltado para as funções que a escrita apresenta, constrói-se uma nova forma de o sujeito se conhecer, se constituir e, como consequência, se tornar um sujeito-autor e não aquele que precisa sempre do copiar/colar ideias de outrem. Ele terá melhores chances de empoderar-se à medida que a escrita fizer parte de seu cotidiano.

Precisamos reconhecer que, para se atingir esses objetivos, não podemos ignorar a formação docente, pois aos professores cabe o papel de formar alunos aptos à escrita autoral, bem construída, adequada ao respectivo contexto de produção e de recepção. Isso requer inicialmente, durante a formação universitária desses profissionais, uma postura mais receptiva ao ato de escrever por parte também dos professores que formam professores, o que pode ser sistematizado com uma nova perspectiva da escrita sem ter apenas um caráter instrumental e utilitário, como uma tarefa que vale nota e, portanto, deve ser realizada. Ainda pode ser relacionada à outra perspectiva de exploração da escrita, em todas as atividades curriculares, como uma prática que necessita ser vista como fundamental, prazerosa e otimizadora de uma formação humana e profissional.

\section{Referências}

BARTHES, Roland [et al.] Escrever ... para que? Para quem? Lisboa: Ed. 70, 1975, p. 255

BIANCHETTI, Lucídio. O processo da escrita: elementos inibidores e facilitadores. In: BIANCHETTI, Lucídio; MEKSENAS, Paulo. (Orgs.). A trama do conhecimento: Teoria, método e escrita em ciência e pesquisa. Campinas/SP: Papirus, 2008. p.334 


\section{usm Eulloabुa}

ISSN: 1984-6444 | http://dx.doi.org/10.5902/1984644430978

BIANCHETTI, Lucídio. Trama e Texto: leitura crítica: escrita criativa. Vol. 1. São Paulo: Summus, 2002, p. 198

BIANCHETTI, Lucídio; MACHADO, Ana Maria Netto. A bússola do escrever: desafios e estratégias na orientação de teses e dissertações. Florianópolis/SC: UFSC, 2000, p. 408

BRASIL. Ministério da Educação. CNE. Conselho Pleno. Resolução no 2, de 1ㅇ de julho de 2015. Disponível em: http://portal.mec.gov.br/escola-de-gestores-daeducacao-basica/323-secretarias-112877938/orgaos-vinculados-82187207/21028resolucoes-do-conselho-pleno-2015. Acesso em: 15 de janeiro de 2018, p.16

CALVINO, Ítalo. Por que ler os clássicos? São Paulo: Companhia das Letras, 1993, p. 279

DEMO, Pedro. Saber pensar. São Paulo: Cortez, 2000, p. 159.

DEMO, Pedro. Pesquisa: princípio científico e educativo. 9. ed. São Paulo: Cortez, 2002, p. 119

EVANGELISTA, Olinda. Devem os alunos escrever? In: EVANGELISTA, Olinda. Trama e Texto: leitura crítica: escrita criativa. Vol. 1. São Paulo: Summus, 2002, p. 198

FREIRE, Paulo. Pedagogia do oprimido. 32. ed. Rio de Janeiro: Paz e Terra, 2002, p. 184

GIRARDELLO, Gilka. A escrita antes do texto: de cozinhas, teares e ateliês. In: BIANCHETTI, Lucídio; MEKSENAS, Paulo. (Orgs.). A trama do conhecimento: Teoria, método e escrita em ciência e pesquisa. Campinas/SP: Papirus, 2008, p. 287300.

GNERRE, Maurizio. Linguagem, escrita e poder. São Paulo: Martins Fontes, 1998, p. 115

KAHNEMAN, Daniel. Rápido e devagar: duas formas de pensar. Rio de Janeiro: Objetiva, 2012.

KLEIMAN, Angela. Texto e leitor: aspectos cognitivos da leitura. 11.ed. Campinas: Pontes, 2013.

KRAMER, Sonia. Escrita, experiência e formação - múltiplas possibilidades de criação de escrita. In: Linguagens, espaços e tempos no ensinar e aprender. ENDIPE. Rio de Janeiro: DP\&A, 2000, p. 105-121. 


\section{usm Eulloabुa}

ISSN: 1984-6444 | http://dx.doi.org/10.5902/1984644430978

KRAMER, Sonia. Leitura e escrita de professores: da prática de pesquisa à prática de formação. Revista Brasileira de Educação, n. 7, p. 19-41, Jan/Fev/Mar/Abr, 1998. Disponível em: http://nead.uesc.br/arquivos/Biologia/modulo_6/situacaoes_de_aprendizagem/materi al_apoio/texto_leitura_e_escrita_de_professores.pdf. Acesso em: 15 de janeiro de 2018.

MECEDO, Lino de; BRESSAN, Rodrigo A. Desafios da aprendizagem: como as Neurociências podem ajudar pais e professores. Campinas/SP: Papirus 7 Mares, 2016, p. 122

MACHADO, Ana Maria Netto. Pânico da folha em branco: para entender e superar o medo de escrever. In: BIANCHETTI, Lucídio; MEKSENAS, Paulo. (Orgs.). A trama do conhecimento: Teoria, método e escrita em ciência e pesquisa. Campinas/SP: Papirus, 2008, p. 267-286.

MARQUES, Mário Osório. Escrever é preciso: o princípio da pesquisa. ljuí: Unijuí, 2001, p. 163

NÓVOA, António; MARCELINO, Francisco; RAMOS, do Ó Jorge. Sérgio Niza: escrito sobre educação. Lisboa: Tinta da China, 2012, p. 709

SOARES, Magda. Letramento: um tema em três gêneros. Belo Horizonte: Autêntica, 1998.

VEIGA-NETO, Alfredo. É preciso ir aos porões. Revista Brasileira de Educação, v. 17 n. 50, p. 267-282, maio-ago./2012.

VYGOTSKY, Lev S.; LURIA, Alexander R.; LEONTIEV, Alex N. Linguagem, desenvolvimento e aprendizagem. São Paulo: Ícone: USP, 1988, p. 228

\section{Correspondência}

Arnaldo Nogaro - Universidade Regional Integrada do Alto Uruguai e das Missões - Av. Sete de Setembro, 1621, Fátima - CEP 99709-910, Erechim, Rio Grande do Sul, Brasil.

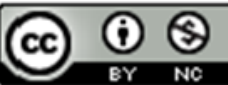

This work is licensed under a Creative Commons Attribution-NonCommercial 4.0 International (CC BY-NC 4.0) 


\section{$=-1$ usm \\ ISSN: 1984-6444

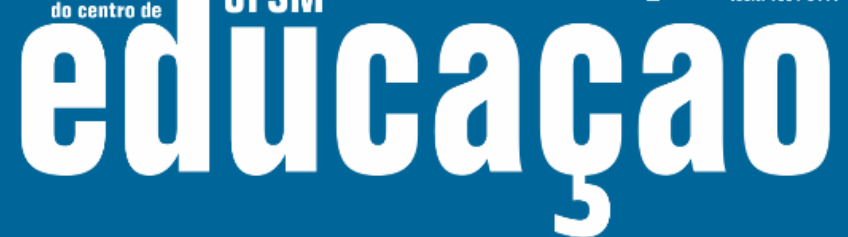

ISSN: 1984-6444 | http://dx.doi.org/10.5902/1984644430978

\section{Notas}

${ }^{1}$ Na Resolução CNE n. 2, de 1 de julho de 2015, por exemplo, um dos princípios da Formação de Profissionais do Magistério da Educação Básica a ser incluídos nos projetos formativos é "a ampliação e o aperfeiçoamento do uso da Língua Portuguesa e da capacidade comunicativa, oral e escrita, como elementos fundamentais da formação dos professores". 